\title{
Prediction of Process Planning By Reorganised Machining Operation Timing of LHB Bogie
}

\author{
Laxmi Kant Rajak ${ }^{1}$, Novel Kumar Sahu ${ }^{2}$ \\ ${ }^{I} M$-Tech Scholar, Department of Mechanical Engineering, GD Rungta College of Engineering \& Technology \\ Bhilai (C.G.) \\ ${ }^{2}$ Assistant Professor, Department of Mechanical Engineering, GD Rungta College of Engineering \& \\ Technology Bhilai (C.G.)
}

\begin{abstract}
The occurrence and characteristics by the configuration of the Process planning on the fabrication, which can have assignment comprising a broad range of activities to design and develop an appropriate fabrication process for producing a fragment. Interpretation of the part design, selection of fabrication processes, definition of operations, process sequences, machining datum's, geometrical dimensions and tolerances are some common activities associated with the assignment. Process planning is also "the association between product design and fabrication" with the supplementary commission to upkeep design of competitive products. Process planning is of a complex and dynamic nature, often managed by a skilled person with uncommon or no explicit methods to solve the task. This paper has comprehensive aim of finding methods that cover essential activities for process planning, together with abilities to predict the outcome of a proposed fabrication process. This is recognized by gathering supporting methods appropriate to manage both qualitative and quantitative characterisation and analyses of a fabrication process
\end{abstract}

Key Words:-Process Planning, Qualitative, Quantitative.

\section{Introduction}

Unpretentious model based on the relationship betweenprocess planning and fabrication covers a wide range of activities needed to specify the fabrication process for a part. Unfortunately, the process planning terminology commonly adopted or standardised definition of what is involved or not, nor for the activities whatever they may be gives a definition that seems to be applicable in supreme cases where process planning is considered. Process planning is defined as the activity of deciding which fabrication processes and machines should be used to accomplish the various operations necessary to produce a component, and the sequence that the processes should follow. Process planning, in the fabrication context, is the determination of processes and resources needed for completing any of the fabrication processes required for converting raw materials into a final product to gratify the design requirements and intent and respect the geometric and technological constraints. Some clarifications are in order to avoid confusions. "Process performance" refers to the accuracy of the process when creating a final part dimension or an LHB dimension. "Process behaviour" is a representation of the manner, or action, of the fabrication process. "Process capability" is enthusiastic to the established conception of PCI where a tolerance range is related to a statistical representation of the process behaviour. If the decided fabrication process cannot balance the product design requirements, as shown in Figure 1, there will be a situation with more out-of-specification parts.

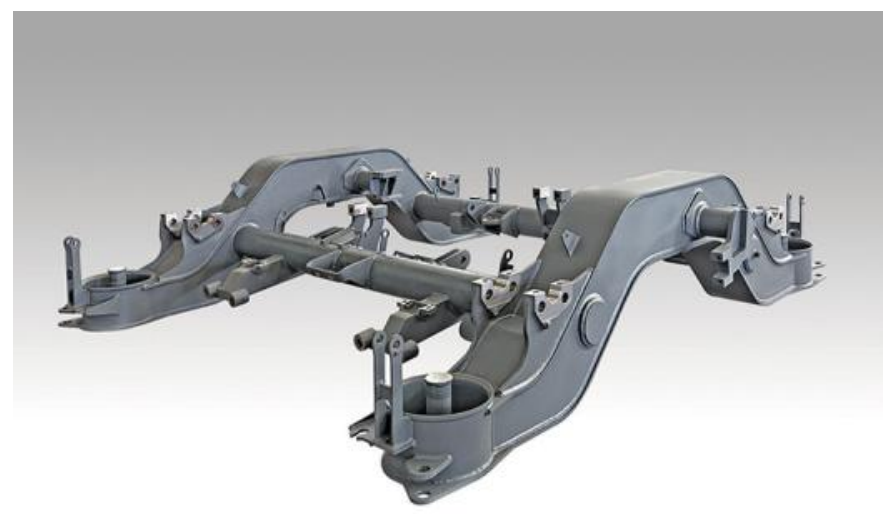

Figure No. 1 LHB Bogie 


\section{Review Work}

Most of the literature agrees that a formal strategic planning process is important for successful development and implementation of a strategic plan. While the processes outlined by various authors may differ, the conclusion is that the use of a process aids in the enlargement of a strategic plan. Additionally, many researchers suggest that effective strategic planning processes embrace an environmental scanning component. Shabana et al. [2] use an analytical track description defined by three step procedure: i)Projection, which define the planar curve obtained by projecting the track centerline onto the horizontal plane; ii) Development, which defines an elevation angle; iii) Super-elevation, which defines the track cant angle. In his formulation, a relationship between the arc-length of actual curve and arc-length of the projected curve is stated. Shabana et al. [5] developed a new elastic force contact formulation for the dynamic simulation of the wheel-rail interaction. In this contact formulation, four surface parameters are introduced in order to be able to describe the geometry of the surfaces of the two bodies that come in contact. The method developed in the mentioned investigation exploits features of multibody computational algorithms that allow adding arbitrary first order differential equations. Meli et al. [7] the contact point position is calculated offline by means of a procedure based on the simplex method. This procedure was used to generate a three dimensional lookup table used in the real-time simulation to find the position of the contact points as a function of wheelset-rail relative displacement, described by three coordinates (the lateral wheelset displacement, the roll and yaw wheelset angle). The procedure was numerically sufficiently efficient and allows multiple contact points to be managed.

\section{Objective}

Product design specifications are with only few exceptions based on quantitative measures.There is a need to estimate the outcome of a proposed fabrication process. There is a need to analyse the effect of potential process plan solutions, parameter settings, IPW tolerances, control strategies, etc. and there has to be one or more methods available where these aspects can be defined and tested. Predicting fabrication process outcome and making comparisons to the design part specification have to be integrated parts of a framework of methods to support process planning. The objective of work has an all-machining timing has to reduce, that cover essential activities for process plan synthesis and analysis, including the possibility to predict the outcome of a proposed process plan. These essential activities are all found in the process flow chart. Much attention is paid to understanding and analysis.

\section{Methodology}

The presented research extends the qualitative approach for organized process planning [3]to include quantitative and analytical methods for design and evaluation of a process plan. A conceptual illustration of the research and development $(\mathrm{R} \& \mathrm{D})$ process for this work is shown in Figure 2. The licentiate thesis "An approach for systematic process planning of gear transmission parts" [4] covers descriptive and qualitative methods for process planning, e.g. how to deal with product design requirements, part and fabrication datums, fabrication operations and fabrication sequence, all with an explanatory approach. The left part of Figure 2 represents this schematic process planning and the tacit, but crucial, knowledge about process behaviour. However, making analyses and predictions of the process plan requires quantification both of the requirements, typically fabrication tolerances, and the behaviour of the included fabrication processes.

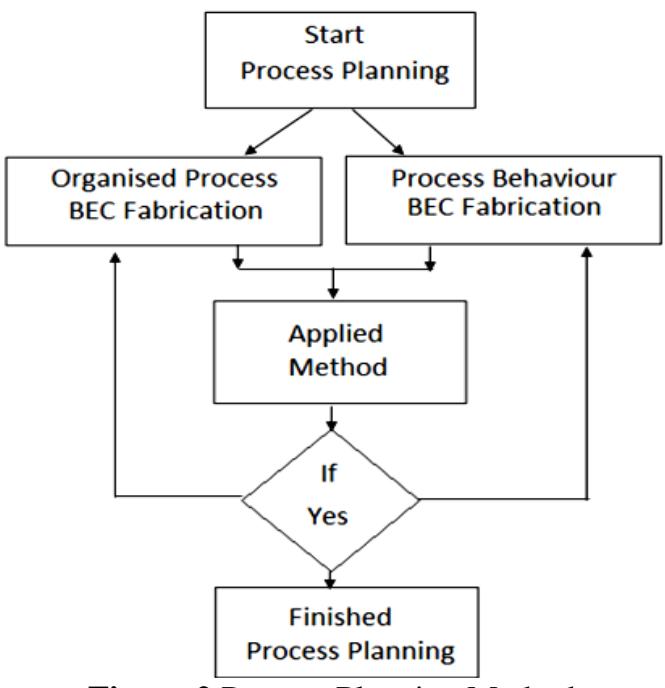

Figure 2 Process Planning Method 
The methodology for organized process planning covers interpretation and transfer of design requirements into the schematic process plan. The organized process plan facilitates explanatory representation of machining or heat treatment operation elements, process sequence and important decisions such as the choice of datum, clamping surfaces and tools. The representation of measuring operations and measuring equipment is done by the same principles. It is desirable to highlight key features derived from both design specification and fabrication process development.

\section{Process Planning}

Development of the procedure for assortment the best variant of process plan would lead through primary process selection (Fabrication, casting etc), sequencing processes and phases, machine tools selection (by help workpiece shape, surface finish, chucking type, cutting parameters), etc. Development of process planning at this project stage means fast, unambiguous, higher level of computerisation process planning. The possible criterions for evaluation of process planning plans are calculation of times (fabrication process), production costs, achievement realization of requested criterions, TQM etc.

- Process planning deals with setting up machines while manufacturing planning refers to setting up the production.

- Process planning associates the design to manufacturing and is very important part of the manufacturing system. Figure 3 shows the role of process planning in manufacturing systems.

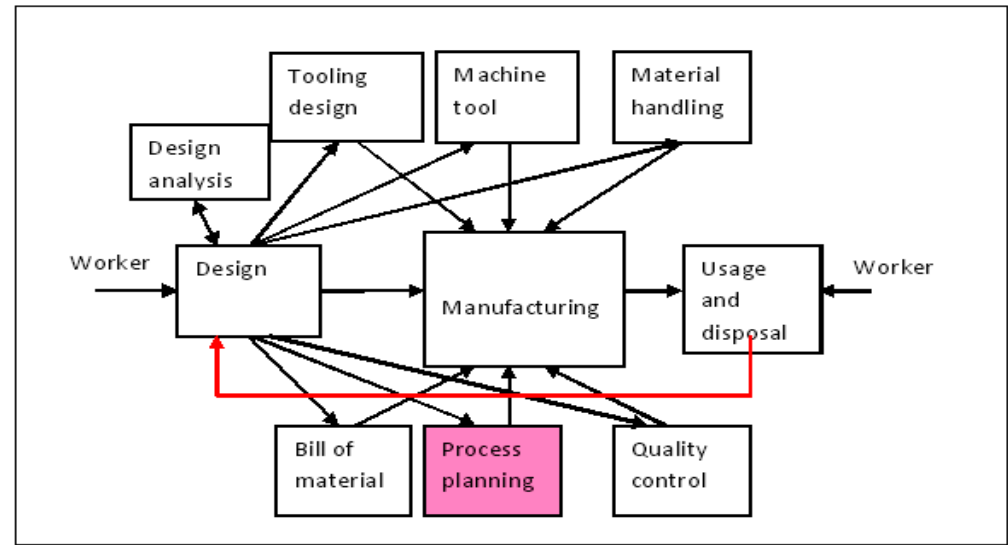

Figure 3 Process planning in Fabrication systems

- Process planning serves as a cohesive linkage between design and manufacturing. It helps to translate design to product

- All manufacturing processes require process plans. However, we will focus on machining process only

\section{Fabrication process details}

Underthis process first preparation of joint has been calculated by machining work these machining work are

- $\quad$ Turning Process shown in Fig 4

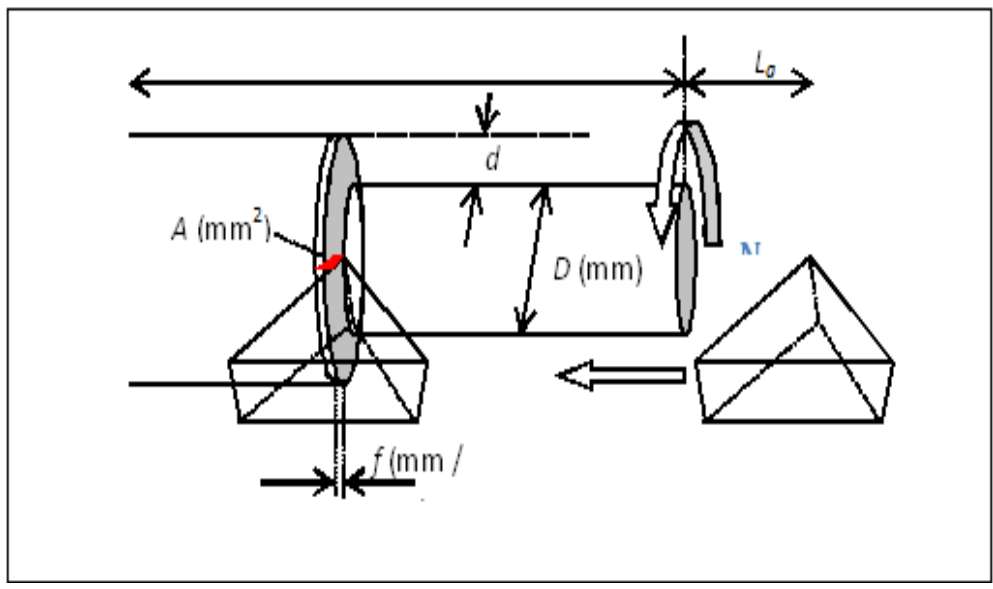

Figure 4 Turning (External) Process 
The imperative parameters include:

- Depth of cut, $d$ (mm or inch)

- $\quad$ Rotation speed, $N$ or $R P M$ (rotation per minute)

- Feed, $f(\mathrm{~mm} /$ rev. $)$, or feed rate, $f_{r}(\mathrm{~mm} / \mathrm{s}$ or inch / s)

- The length of cut, $L$ (mm or inch)

Turning is termed single point cutting as there is only one point (the cutting edge) engaged in the cut in any given time. Some elementary calculations in turning

- $\quad$ Cutting speed, $V(\mathrm{~mm} / \mathrm{m}$ or inch $/ \mathrm{m})$ :

- $\quad$ Machining time (minute):

$$
V=\pi D N
$$

$T_{c}=\frac{L+L_{a}}{f N}$

Where, $L_{a}$ is the allowance distance ( $\mathrm{mm}$ or inch).

- $\quad$ Material removal rate, $M R R,\left(\mathrm{~mm}^{3} / \mathrm{min}\right.$, or inch $\left.^{3} / \mathrm{min}\right)$ :

$M R R=D N f d$

$V T^{n}=C$

Tool life (Taylor's formula), $T$ (min):

Where, $n$ is a tool material dependent constants, $C$ is the cutting speed on which the tool life is one minute. In individual for HSS tools $n \approx 0.1$, for carbide tools, $n \approx 0.2$, and for ceramic tools, $n \approx 0.4$. The constant $C$ is dependent on the work material and its value can be found from manufacturing references by worker of BEC. In particular for low carbon steels $C \approx 500$ so the cutting force $F$ :

$F=F_{s} A$

Where, $F_{s}$ is the specific energy and

$A=d \bullet f$ is the area of cutting.

The specific cutting force is a utility of many factors such as work material, tool geometry, for low carbon steels, $F_{s} \approx 58.15 \mathrm{MPa}$.

Required Work piece dimensions are:

- $D=100 \mathrm{~mm}$

- $d=0.2 \mathrm{~mm}$

- $f=0.1 \mathrm{~mm} / \mathrm{rev}$.

- $L+L_{a}=200 \mathrm{~mm}$

- $\quad N=600 \mathrm{rev} . / \mathrm{min}$

- $n=0.2$ (carbide cutter)

- $C=500 \mathrm{~m}$ (low carbon steels)

The cutting speed

$V=\pi D N=188485.59(\mathrm{~mm} / \mathrm{min})=188.5(\mathrm{~m} / \mathrm{min})=3.14(\mathrm{~mm} / \mathrm{s})$

Note that $(\mathrm{m} / \mathrm{min})$ is usually used.

The material removal rate

$$
\begin{aligned}
M R R= & \pi D N f d=37699.1((\mathrm{~mm})(1 / \mathrm{min})(\mathrm{mm})(\mathrm{mm})] \\
& =37.699 \mathrm{~mm}^{3} / \mathrm{min} \\
& =628 \mathrm{~mm}^{3} / \mathrm{sec}
\end{aligned}
$$

The tool life

$$
T=\left(\frac{500}{196}\right)^{1 / 0.2}\left(\frac{m}{m / \min }\right)=108 \mathrm{~min} .
$$

The machining time per parts

$$
T_{c}=\frac{L+L_{a}}{f N}=\frac{200}{0.1 * 600}\left(\frac{\mathrm{mm}}{(\mathrm{mm} / \mathrm{rev})(\mathrm{rev} / \mathrm{min})}\right)=3.33 \mathrm{~min}
$$




\section{Determining the Milling cutting condition}

There are many models available. However, we will discuss the minimum unit cost model only.

- $\quad$ Replicating a machining operation, the unit cost, $C_{u}$, is:

$C_{u} \quad=\quad$ non-production cost per unit (loading, unloading, setup)

$+\quad$ machining cost per unit (machining time $\mathrm{x}$ constant)

$+\quad$ tool amendment cost per unit

$+\quad$ tooling cost per unit

- $\quad$ Thus, the minimum unit cost model:

$$
C_{u}=C_{0} t_{1}+C_{0} t_{c}+C_{0} t_{d}\left(\frac{t_{c}}{T}\right)+C_{t}\left(\frac{t_{c}}{T}\right)
$$

where, $C_{0}-$ machining cost with overhead $(\$ / \mathrm{min})$

$$
\begin{aligned}
& t_{1} \text { - non-production time }(\mathrm{min}), \\
& t_{c} \text { - machining time }(\mathrm{min}), \\
& t_{c} \text { - tool change time }(\mathrm{min}), \\
& \left(t_{c} / T\right) \text { - percentage of tool life used per unit, } \\
& C_{t}-\text { tool cost (per edge) }(\$)
\end{aligned}
$$

Reminder that the machining time is the most important time which is depend on the worker cost.

The machining time is:

$$
T_{c}=\frac{L}{f N}=\frac{\pi D L}{f v}\left(\frac{m m^{*} m m}{m m^{*} m / \min }\right)=\frac{\pi D L}{1000 f v}(\min )
$$

the tool life is:

$$
T=\left(\frac{C}{v}\right)^{1 / n}(\min )
$$

Substitute the machining time and the tool life equation to the primary equation, it follows that:

$$
C_{u}=C_{0} t_{1}+C_{0}\left(\frac{\pi L D}{1000 v f}\right)+C_{0}\left(\frac{\pi L D}{1000 v f}\right)\left(\frac{v}{C}\right)^{1 / n} t_{d}+C_{t}\left(\frac{\pi L D}{1000 v f}\right)\left(\frac{v}{C}\right)^{1 / n}
$$

The solution of this exemplary can be found by partial differentiating the equation, equating to zero and solving; and the result is as follows (fortunately, somebody has solved it for us):

$$
v^{*}=\frac{C}{\left[\left(\frac{1}{n}-1\right)\left(\frac{C_{0} t_{d}+C_{t}}{C_{0}}\right)\right]^{n}}
$$

and the resulting machining time is:

$$
T^{*}=\left(\frac{1}{n}-1\right)\left(\frac{C_{0} t_{d}+C_{t}}{C_{0}}\right)
$$

- The other commonly used model is production rate model, which will be discussed in the tutorial together with the cutting lead time. Dimension which accomplish by machine are given below:

- The parts: 50 units, $L=300 \mathrm{~mm}, D=60 \mathrm{~mm}, f=0.2 \mathrm{~mm} / \mathrm{rev} ., d=1 \mathrm{~mm}$,

- The ratio of tool to tool life coefficient: $n=0.2 \& C=200$,

- Machining cost: machining labor cost $\$ 10 / \mathrm{hr}$, overhead $=50 \%$,

- Tooling cost: tool cost $\$ 30.96,6$ edges,

- Tool change time $t_{d}=0.5 \mathrm{~min}$.

\section{Evaluation:}

- The optimal cutting speed:

$$
v^{*}=\frac{C}{\left(T^{*}\right)^{n}}=82.337 \mathrm{~m} / \mathrm{min}
$$

- $\quad$ The optimal machining time: 


$$
T^{*}=\left(\frac{1}{n}-1\right)\left(\frac{C_{0} t_{d}+C_{t}}{C_{0}}\right)=84.56 \mathrm{~min}
$$

\section{Production Schedule}

The aggregate production plan is an overall plan that balances the total customer orders and production capability of the company. After the aggregate production plan is delivered, the next step is to develop master production schedules, which specify when each and every product shall be made.

- There are two correlated terms: master production schedule and production operations schedule.

- Master production schedule deals with the overall time schedule problems of the production such as whether overtime is necessary. It is usually easier to conduct.

- Operations schedule deals with Machine loading - how to assign the jobs to the work centers (workstations) and when

- Job sequencing - which job shall be done first and when

- We will focus on operations schedule.

- The objectives of operations schedule may be

- Meet the due dates

- Minimize manufacturing throughput time

- Minimize work-in-process

- Maximize work center utilization

- There are two important indices in operations scheduling:

- $\quad$ Loading time $=$ setup time $+\mathrm{Q} *$ unit run time (processing time)

- Manufacturing throughput time $=$ setup time $+\mathrm{Q} *$ unit run time + move and queue time, where, $\mathrm{Q}$ is the lot size (processing time + waiting time).

The basic rules of operations schedule include:

(a) First-come, first-served (FCFS): assign jobs on a first-come, first-served basis.This rule is blind with admiration to all other factors such as due date and urgency.

(b) Shortest processing time (SPT): give the maximum priority to the jobs with the shortest processing time (so it can get a higher cash flow). These rule outcomes in the lowest mean completion time and hence, the lowest work-in-process inventory.

(c) Earliest due date (EDD): give the maximum priority to the jobs with the initial due date.

(d) Least slack (LS): assign the highest priority to the job with lowest day of slack. The slack is defined as follows:

Slack $=$ time remaining until due date process time remaining

(e) Least slack per operation (LSPO): assign priority based on the smallest value obtained by dividing the slack by the number of remaining operations

(f) Critical ratio (CR): assign priority based on a critical index defined below:

$$
C R=\frac{\text { time remaining until due date }}{\text { lead time remaining }}
$$

Where, time remaining up to due data $=$ due date - now and lead time includes setup, run, move, and queue times.

Now BEC fabrication workshop LHB bogie frame preparation time has been taken where multiple jobs enter a work center as shown below:

BEC fabrication complete LHB bogie Frame in Four steps which are side frame left, side frame right, brake beam assembly and Bracket assembly sequentially with the expected due date, the remaining process time and the number of remaining operations shown in Fig 5.

- Using different rules, different job sequences may be obtained.

- Use the rule first-come, first-serve (FCFS): side frame left, side frame right, brake beam assembly and Bracket assembly.

- Use the rule shortest production time (SPT): side frame left, brake beam assembly, Bracket assembly and side frame right

- Use the rule earliest due date (EDD): side frame left, Bracket assembly, brake beam assembly and side frame right. 


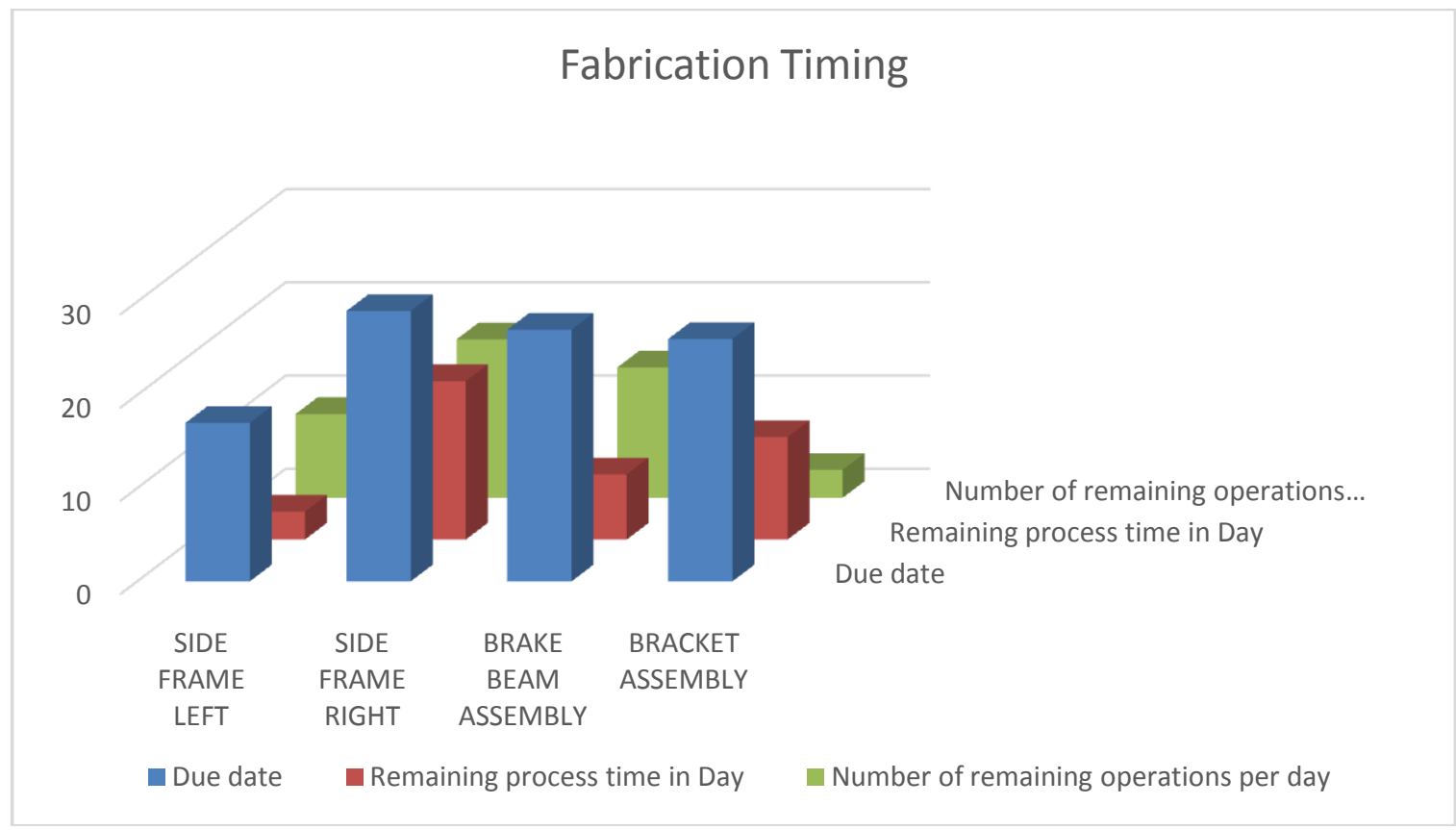

Figure 5 Processing time to finished product

\section{Conclusion}

As seen in the Fig 5 the remaining process timing of side frame right pats have consuming maximum time whereas the side frame left part have the lowest remaining process timing, so it need to require the save process time has give to the side frame right for that the smooth process can be obtain and all parts of bogie will finished in approximately same duration. Process planners tend to be aware of time-consuming, regularized, activities that have to be done but do not require much process planning skill, like creation of work instructions and fabrication of LHB. As process planning has a decisive impact on product quality and a considerably high influence on machining cost, the possibilities to efficiently cost and evaluate a process plan is of great interest. In this case the process is diverted on the milling section which gives huge difference in cost of machining work. In this case side frame left part should be predicted to cover the process of rest of all the parts for smooth process planning.

\section{Reference}

[1]. Anderberg, S., 2012. Methods for improving performance of process planning for CNC machining - An approach based on surveys and analytical models. Göteborg: Chalmers University of Technology.

[2]. A. A. Shabana, K. E. Zaazaa, and H. Sugiyam. Rail Road Vehicle Dynamics: A Computational Approach. CRC Press, Taylor and Francis group, New York, 2008.

[3]. A. Shabana. Dynamics of Multibody Systems, Second Edition. Cambridge University Press, Cambridge, United Kingdom, 1998.

[4]. A. Shabana and J. R. Sany. A survey of rail vehicle track simulation and flexible multibody dynamics. Nonlinear Dynamics, 26, 2001.

[5]. A. A. Shabana, K. E. Zaazaa, J. L. Escalona, and J. R. Sany. Development of elastic force model for wheel/rail contact problems. Journal of Sound and Vibration, 269, 2004.

[6]. A. Shabana, R. Chamorro, and C. Rathod. A multi-body system approach for finite-element modelling of rail flexibility in railroad vehicle applications. Proc. IMechE, Part K: Journal of Multi-body, 222(1), 2008

[7]. E. Meli, M. Malvezzi, S. Papini, L. Pugi, and A. Rindi. A railway vehicle multibody model for real-time application. Vehicle System Dynamics, 46(2), 2008. 